\title{
Consumo e Absorção Aparente Total de Macroelementos Inorgânicos (Ca, P, Mg, Ke Na), em Bezerros da Raça Holandesa Alimentados com Dietas Contendo Diferentes Níveis de Volumoso ${ }^{1}$
}

\section{Ricardo Dias Signoretti ${ }^{2}$, José Fernando Coelho da Silva ${ }^{3}$, Sebastião de Campos Valadares Filho $^{3}$, José Carlos Pereira ${ }^{3}$, Paulo Roberto Cecon ${ }^{4}$, Augusto César de Queiroz ${ }^{3}$, Gherman Garcia Leal de Araújo ${ }^{5}$, Giselle Mariano Lessa de Assis ${ }^{6}$}

\begin{abstract}
RESUMO - Este estudo visou avaliar os efeitos dos diferentes níveis de volumoso nas dietas sobre os consumos e as absorções aparentes de cálcio $(\mathrm{Ca})$, fósforo $(\mathrm{P})$, magnésio $(\mathrm{Mg})$, potássio $(\mathrm{K})$ e sódio $(\mathrm{Na})$. Trinta e cinco bezerros da raça Holandesa puros por cruzamento, não-castrados, com idade média de 60 dias e peso vivo inicial de $78 \mathrm{~kg}$, foram distribuídos em delineamento inteiramente casualizado, com nove repetições por dieta, exceto para a dieta com 10\% de volumoso, com oito repetições. Os animais foram alimentados à vontade com dietas contendo níveis de 10, 25, 40 e 55\% de volumoso, na base da MS, usando-se feno de capim coast-cross (Cynodon dactylon), fubá de milho e farelo de soja, os quais constituíram dietas com aproximadamente 16\% de PB. Os coeficientes de absorção aparente foram obtidos por intermédio de ensaios de digestibilidade, realizados aos 120 e 180 dias de idade dos animais, sendo usado como indicador o óxido crômico para estimar a excreção fecal. O consumo máximo diário de 10,96 $\mathrm{g}$ de $\mathrm{P}$ foi estimado com 42,40\% de volumoso na dieta. Os consumos de Mg e K aumentaram, o de Na decresceu linearmente e o de Ca não foi influenciado com o aumento de volumoso na dieta. Os coeficientes de absorção aparente de Ca, P, Mg e Na não foram influenciados, enquanto o de $\mathrm{K}$ decresceu linearmente com aumento dos níveis de volumoso nas dietas. Os consumos de $\mathrm{P}$, $\mathrm{Mg}$, $\mathrm{K}$ e $\mathrm{Na}$ e a absorção aparente de $\mathrm{K}$ foram influenciados pelos níveis de volumoso nas dietas.
\end{abstract}

Palavras-chave: absorção aparente, bezerro holandês, consumo, mineral, nível de volumoso

\section{Intake and Apparent and Total Absorption of Inorganic Macroelements (Ca, P, Mg, K and Na) in Holstein Calves Fed Diets with Different Levels of Forage}

ABSTRACT - This study was to evaluate the effects of different levels of forage in the diet on the intake and apparent absorption of calcium $(\mathrm{Ca})$, phosphorus $(\mathrm{P})$, magnesium $(\mathrm{Mg})$, potassium $(\mathrm{K})$ and sodium $(\mathrm{Na})$. Thirty five pure Holstein bull calves, 60 days old with initial average live weight (LW) of $78 \mathrm{~kg}$, were allotted in a completely randomized experimental design with nine replicates per diet, except for the $10 \%$ forage diet, with eight replications. The animals were ad libitum fed with diets contained $10,25,40$ and 55\% of forage, on the DM basis, using chopped coast-cross (Cynodon dactylon) grass, ground corn and soybean meal, which constitutes diets with approximately $16 \% \mathrm{CP}$. The apparent absorption coefficients were obtained by means of digestibility trials, carried out at 120 and 180 days of the animals age, being used the chromium oxide as a marker to estimate the fecal excretion. The maximum daily intake of $10.96 \mathrm{~g}$ of $\mathrm{P}$ was estimated with $42.40 \%$ of forage in the diet. The intakes of $\mathrm{Mg}$ and $\mathrm{K}$ increased, while the $\mathrm{Na}$ decreased linearly and the $\mathrm{Ca}$ was not affected by the forage level in the diet. The apparent absorption of Ca, $\mathrm{P}, \mathrm{Mg}$ and $\mathrm{Na}$ were not affected, while the $\mathrm{K}$ decreased linearly with the forage levels in the diets. The intakes of $\mathrm{P}, \mathrm{Mg}, \mathrm{K}$ and $\mathrm{Na}$ and apparent absorption of the $\mathrm{K}$ were affected by the forage levels in the diets.

Key Words: apparent absorption, Holstein calf, intake, mineral, forage level

\footnotetext{
${ }^{1}$ Parte da tese apresentada à UFV, pelo primeiro autor como um dos requisitos para obtenção do Título de Doutor em Zootecnia. Área de concentração: Nutrição de Ruminantes.

2 Eng.-Agr., aluno de Doutorado em Zootecnia do DZO/UFV, Bolsista da CAPES.

3 Professor do DZO/UFV - 36571-000 - Viçosa, MG, Bolsista do CNPq.

${ }^{4}$ Professor do Departamento de Matemática da UFV.

5 Pesquisador do EMBRAPA - CPATSA - 56300-000 - Petrolina, PE.

${ }^{6}$ Bolsista de IC, CNPq.
} 


\section{Introdução}

As espécies bovinas devem receber, durante todo o seu ciclo de vida, além dos demais nutrientes, macro e microelementos inorgânicos em quantidades e proporções adequadas, para garantir seu desempenho máximo.

O conteúdo e a disponibilidade dos minerais dos alimentos são importantes para a efetiva formulação de dietas, bem como no controle da poluição ambiental provocada pela inclusão de níveis excessivos de minerais nas dietas (KHORASANI et al., 1997). Contudo, os dados sobre o local de absorção e a disponibilidade de $\mathrm{Ca}, \mathrm{P}, \mathrm{Mg}$, K e Na são limitados (COELHO DA SILVA, 1995).

O cálcio é o macroelemento inorgânicomais abundante no organismo animal e importante em muitas funções do metabolismo no corpo, principalmente nos ossos.

A quantidade de $\mathrm{Ca}$ absorvida pelo animal está relacionada com ingestão de $\mathrm{Ca}$, "status" de $\mathrm{Ca}$ do animal, idade do animal, quantidade requerida de $\mathrm{Ca}$, fonte e fórmula química que o Ca ocorre na dieta, "status" de vitamina D do animal e inter-relação com outros elementos inorgânicos (McDOWELL et al. 1983; REID et al., 1987; ALFARO et al., 1988; e NRC, 1989 e 1996).

Os coeficientes de absorção aparente total de cálcio relatados pela literatura, em diferentes sistemas de alimentação, foram, em média, de 33,0 a 68,0\% (FIELD, 1983), 23,4\% (COELHO DA SILVA et al., 1991), 47,9\% (VALADARES FILHO et al.,1991a), 36,2\% (ARAÚJO et al., 1994), 32,8\% (RABELLO et al., 1994), 15,0 a 68,0\% (COELHO DA SILVA, 1995), 26,2\% (BEN-GHEDALIA et al., 1996), 63,25\% (MORA et al., 1996), 52,56\% (ARAÚJO et al., 1997), 16,32\% (CARVALHO et al., 1997) e 29,87\% (KHORASANI et al., 1997).

Com o aumento da idade de bovinos, a absorção verdadeira de cálcio diminuiu de $98 \%$, em bezerros alimentados com leite, para 22\%, nos animais à maior maturidade (TEIXEIRA, 1992).

Para bezerros após a desmama, o valor sugerido para absorção real de cálcio é de $68 \%$. É importante observar que a absorção de $\mathrm{Ca}$ é controlada por mecanismo homeostático e está inversamente relacionada com o teor de $\mathrm{Ca}$ na dieta, ou melhor, com a proporção de $\mathrm{Ca}$ na dieta em relação à exigência líquida de $\mathrm{Ca}$ (BOIN, 1993).

O NRC $(1989,1996)$ mencionou que a absorção verdadeira de $\mathrm{Ca}$ em novilhos jovens foi de 38 e $50 \%$, respectivamente.

Em experimentos realizados no Brasil, o coeficiente médio de absorção real de $\mathrm{Ca}$ em animais castrados e não-castrados da raça Holandesa, na fase final de crescimento, foi de 71,6\% (COELHO DA SILVA, 1995).

A quantidade de fósforo absorvido modificou-se com fonte, quantidade consumida, relação $\mathrm{Ca}: \mathrm{P}$, status de vitamina $\mathrm{D}$, pH intestinal, idade do animal, ingestão dietética de outros minerais, fórmula química na qual ocorre a dieta, variação entre animais e níveis dietéticos de $\mathrm{Ca}, \mathrm{Fe}, \mathrm{Al}, \mathrm{Mn}, \mathrm{K}, \mathrm{Mg}$ e gordura, além de outros (ARC, 1980; McDOWELL et al., 1983; HORST, 1986; REID et al., 1987; e NRC, 1989).

MORSE et al. (1992) relataram aumento na excreção fecal de $\mathrm{P}$ em resposta ao aumento do $\mathrm{P}$ dietético, sendo que, do total excretado, 60,50; 0,90; e $26,70 \%$ foram excretados nas fezes, na urina e no leite, respectivamente.

$\mathrm{O}$ nível de $\mathrm{P}$ adequado é necessário para manter a ótima ingestão de alimentos, o desenvolvimento do esqueleto, o crescimento microbiano e a digestão da celulose e o crescimento corporal (Teh et al., 1982, citados por JACKSON et al., 1988).

Os coeficientes de absorção aparente de fósforo variaram nos diferentes sistemas de alimentação utilizados em diversos trabalhos revisados, sendo 57,70\% (COELHO DA SILVA et al., 1991), 45,80\% (ROSADO, 1991), 44,30\% (VALADARES FILHO et al., 1991a), 43,60\% (ARAÚJO et al., 1994), 42,20\% (BENGHEDALIA et al., 1996), 57,48\% (MORA et al., 1996), 51,90\% (ARAÚJO et al., 1997), 30,50\% (CARVALHO et al., 1997) e 30,90\% (KHORASANI et al., 1997).

O ARC (1980), o NRC (1989) e o AFRC (1991) adotaram absorções verdadeiras de $\mathrm{P}$ de $50,58 \mathrm{e}$ $70 \%$, respectivamente. A absorção de $\mathrm{P}$ variou com a idade do animal, observando-se redução na eficiência de absorção acima de 14 meses de idade (ARC, 1980; NRC, 1989).

O coeficiente de absorção real de fósforo em animais castrados e não-castrados da raça Holandesa, na fase final de crescimento, obtidos em pesquisas realizadas no Brasil, foi de 63\% (COELHO DA SILVA, 1995).

O coeficiente de absorção aparente de fósforo foi de 78 e 58\% para bezerros até 1 ano de idade e animais acima de 1 ano, respectivamente, ambos alimentados com dietas contendo diferentes proporções de volumoso e concentrado (BOIN, 1993).

Segundo o NRC (1996), o rúmen é o principal local de absorção de $\mathrm{Mg}$, em ruminantes. Contudo, a absorção de $\mathrm{Mg}$ é maior em animais jovens alimentados com leite, mas diminui com o avanço da idade.

Algumas pesquisas relataram que o aumento dos níveis dietéticos de $\mathrm{K}$ em ruminantes resultou em 
180 Rev. bras. zootec.

maior fluxo de $\mathrm{Mg}$ no duodeno proximal, reduzindo, conseqüentemente, a digestibilidade de $\mathrm{Mg}$ no trato total (GREENE et al., 1983; KHORASANI e ARMSTRONG, 1990).

Os resultados médios verificados na literatura referentes à absorção aparente de $\mathrm{Mg}$ variaram amplamente nas diferentes dietas, sendo 18,4\% (GREENE et al., 1988), 16,3\% (COELHO DA SILVA et al., 1991), 43,7\% (ROSADO,1991), 56,9\% (VALADARES FILHO et al.,1991b), 51,5\% (ARAÚJO et al.,1994), 36,6\% (RABELLO et al., 1994), 37,5\% (BEN-GHEDALIA et al., 1996), 41,6\% (MORA et al., 1996), 45,07\% (ARAÚJO et al., 1997), 23,7\% (CARVALHO et al., 1997) e 20,23\% (KHORASANI et al., 1997).

O coeficiente de absorção real de magnésio para animais castrados e não-castrados da raça Holandesa, na fase final de crescimento, em ensaios de digestão realizados no Brasil, foi, em média, de 35,7\% (COELHO DA SILVA, 1995). Os valores sugeridos para absorção aparente de magnésio em bezerros com peso vivo de 50,75 e $100 \mathrm{~kg}$ foram de 70,30, $20 \%$, respectivamente (ARC,1980).

Segundo KHORASANI et al. (1997), o intestino delgadoé o principal local de absorção de potássio, porém, quando o consumo é muito alto, o K será mais absorvido antes do intestino delgado. No entanto, o NRC (1996) mencionou que o potássioé absorvido no rúmen e omaso, bem como no intestino, e a absorção é muito alta.

Alguns resultados médios obtidos na literatura, referentes à absorção aparente de $\mathrm{K}$, variaram amplamente entre dietas, sendo 83,4\% (COELHO DA SILVA et al., 1991), 44,4\% (ROSADO, 1991), 67,9\% (VALADARES FILHO et al., 1991b), 80,8\% (ARAÚJO et al., 1994), 85,0\% (RABELLO et al., 1994), 77,0\% (RAHNEMA et al., 1994), 83,05\% (BENGHEDALIA et al., 1996), 79,4\% (MORA et al., 1996), 82,32\% (ARAÚJO et al., 1997), 70,3\% (CARVALHO et al.,1997) e $82,1 \%$ (KHORASANI et al.,1997). O NRC (1989) mencionou que o coeficiente de absorção verdadeira variou de 91 a $100 \%$.

Os ruminantes têm grande apetite pelo sódio, porém, quando fornecido à vontade, os animais podem consumir quantidade maior que o seu requerimento (NRC, 1996).

Em revisões de literatura realizadas sobre a absorção aparente de sódio, verificou-se ampla variação entre as dietas utilizadas nestes ensaios, em média, de 75,5\% (COELHO DA SILVA et al., 1991), 56,5\% (ROSADO, 1991), 59,2\% (VALADARES FILHO et al., 1991b), 80,5\% (RABELLO et al.,
1994), 77,2\% (BEN-GHEDALIA et al., 1996), 68,9\% (MORA et al., 1996), 93,64\% (ARAÚJO et al., 1997), 89,1\% (CARVALHO et a., 1997) e 76,13\% (KHORASANI et al., 1997). O ARC (1980) adotou o valor de $91 \%$ para absorção verdadeira de sódio.

$\mathrm{O}$ coeficiente médio de absorção real de $\mathrm{Na}$ para animais castrados e não-castrados da raça Holandesa, na fase final de crescimento, em ensaios realizados no Brasil, foi de 53,5\% (COELHO DA SILVA, 1995).

Devido à importância com que macroelementos inorgânicos específicos influem nos microrganismos ruminais, a eficiência de absorção e o metabolismo dos nutrientes e, conseqüentemente, o desempenho animal, aliado à existência de poucas informações na literatura, sobre os consumos e as absorções de macroelementos inorgânicos nas dietas de bezerros da raça Holandesa, objetivou-se, neste trabalho, avaliar o efeito de diferentes níveis de volumoso sobre os consumos e as absorções aparentes de $\mathrm{Ca}, \mathrm{P}, \mathrm{Mg}, \mathrm{K}$ e Na, utilizando-se 35 bezerros da raça Holandesa puros por cruza, em confinamento.

\section{Material e Métodos}

O local e o período de realização do experimento, os animais, o manejo alimentar e as amostragens foram descritos por SIGNORETTI et al. (1999).

Nos estudos de consumo e absorção aparente de cálcio $(\mathrm{Ca})$, fósforo $(\mathrm{P})$, magnésio $(\mathrm{Mg})$, potássio $(\mathrm{K})$ e sódio $(\mathrm{Na})$, foram formuladas dietas com base nas exigências nutricionais, segundo as normas do NRC (1989), para ganho esperado de 1,0 kg/dia.

Foram utilizados sistemas de alimentação (tratamentos), com os seguintes níveis de feno de capim coast-cross (Cynodon dactylon) na base da matéria seca (MS): 10, 25, 40 e 55\% para os tratamentos $1,2,3$ e 4, respectivamente. Os teores dos macroelementos inorgânicos das dietas na base MS encontram-se na Tabela 1.

As estimativas das absorções aparentes de $\mathrm{Ca}, \mathrm{P}$, $\mathrm{Mg}, \mathrm{K}$ e $\mathrm{Na}$ foram obtidas a partir de ensaios de digestão realizados aos 120 e 180 dias de idade dos animais. Foram fornecidos $5 \mathrm{~g}$ de óxido crômico, via oral, divididos em doses de 2,5 g cada, às 9 e $15 \mathrm{~h}$, durante 16 dias, sendo 10 dias de período de adaptação e seis dias para o período de coleta de fezes.

As amostragens dos alimentos, das sobras e das fezes e o processamento das mesmas foram realizados conforme SIGNORETTI et al. (1999).

As determinações dos macroelementos inorgânicos foram feitas na solução mineral, por intermédio da 
Tabela 1 - Teores de matéria seca (MS), cálcio (Ca), fósforo $(\mathrm{P})$, magnésio $(\mathrm{Mg})$, potássio $(\mathrm{K})$ e sódio $(\mathrm{Na})$

Table 1 - $\quad \operatorname{Drymatter}(D M)$, calcium (Ca), phosphorus $(P)$, magnesium $(\mathrm{Mg})$, potassium $(\mathrm{K})$ and sodium $(\mathrm{Na})$ contents

\begin{tabular}{lcccc}
\hline & \multicolumn{4}{c}{ Nível de volumoso (Level of forage), $\%$} \\
\cline { 2 - 5 } Item & 10 & 25 & 40 & 55 \\
\hline $\mathrm{MS}(D M), \%$ & 87,43 & 87,45 & 87,39 & 87,51 \\
$\mathrm{Ca}^{1}$ & 0,54 & 0,51 & 0,52 & 0,55 \\
$\mathrm{P}^{1}$ & 0,20 & 0,20 & 0,25 & 0,22 \\
$\mathrm{Mg}^{1}$ & 0,11 & 0,12 & 0,13 & 0,13 \\
$\mathrm{~K}^{1}$ & 0,92 & 1,06 & 1,28 & 1,45 \\
$\mathrm{Na}^{1}$ & 0,16 & 0,12 & 0,13 & 0,10 \\
\hline Porcentagem da MS (DM percentage).
\end{tabular}

digestão via-úmida. Após as devidas diluições, o Ca e o $\mathrm{Mg}$ foram determinados por espectrofotometria de absorção atômica, o P por colorimetria e o K e o Na por espectrofotometria de chama, conforme SILVA(1990).

O delineamento utilizado foi inteiramente casualizado, com quatro tratamentos e nove repetições, excetuando-se o primeiro tratamento, com oito repetições. As variáveis estudadas foram interpretadas por meio de análises de variância e regressão, utilizando-se o programa computacional SAEG. Os coeficientes de regressão foram comparados pelo teste " $t$ ", adotando-se os níveis de 1 e $5 \%$ de probabilidade.

\section{Resultados e Discussão}

Os consumos médios de cálcio $(\mathrm{Ca})$, fósforo $(\mathrm{P})$, magnésio $(\mathrm{Mg})$, potássio $(\mathrm{K})$ e sódio $(\mathrm{Na})$, em gramas por dia, e seus respectivos coeficientes de variação e as equações de regressão ajustadas encontram-se na Tabela 2.

Observou-se comportamento quadrático para o consumo de $\mathrm{P}$, estimando-se o consumo máximo de 10,96 g/dia para o nível de $42,40 \%$ de volumoso na dieta.

Com relação aos consumos de $\mathrm{P}$, verificaramse, para todos os níveis de volumoso, valores foram inferiores aos recomendados pelo NRC (1989), para um bovino macho não-castrado de grande porte, pesando $200 \mathrm{~kg}$ e ganhando $800 \mathrm{~g} / \mathrm{dia}$, que foi de $15 \mathrm{~g}$ de $\mathrm{P}$.

$\mathrm{O}$ consumo de Ca não foi influenciado pelos níveis de volumoso, no entanto, verificou-se que os mesmos foram semelhantes aos recomendados pelo NRC (1989), para um bovino macho não-castrado de grande porte, pesando $200 \mathrm{~kg}$ e ganhando $800 \mathrm{~g} / \mathrm{dia}$, que foi de $22 \mathrm{~g}$ de $\mathrm{Ca}$.

Os consumos de $\mathrm{Mg}$ e K aumentaram, enquanto o de $\mathrm{Na}$ decresceu linearmente com adição de volumoso nas dietas.
Em outros trabalhos realizados no Brasil, CARVALHO et al. (1997), usando bovinos zebuínos, com idade média de 18 meses e peso vivo inicial de $186 \mathrm{~kg}$, que receberam dietas com níveis crescentes de concentrado $(20,0 ; 32,5 ; 45,0 ; 57,5$ e 70,0\%), verificaram efeito quadrático para os consumos de $\mathrm{P}$, estimandose consumo máximo com $43 \%$ de concentrado nas rações. Houve efeito linear decrescente para o consumo de $\mathrm{Mg}$, enquanto os consumos de $\mathrm{Ca}$ e $\mathrm{K}$ não foram influenciados pelos níveis de concentrado nas rações. ARAÚJO et al. (1997), usando bezerros mestiços Holandês x Zebu, com idade média de 60 dias e peso inicial médio de $60 \mathrm{~kg}$, alimentados com níveis de 10, 25, 40, 55 e 90\% de feno de capim coastcross na dieta, verificaram comportamento quadrático para os consumos de $\mathrm{Ca}, \mathrm{P}, \mathrm{Mg}$ e $\mathrm{K}$. Os consumos máximos estimados foram de 56,6; 14,2; 4,7 e 41,1 g/ dia para níveis de 47,0;30,0; 45,3 e 51,8\% de volumoso, para $\mathrm{Ca}, \mathrm{P}, \mathrm{Mg}$ e $\mathrm{K}$, respectivamente.

FERREIRA (1997) usou bovinos mestiços $F_{1}$ Simental x Nelore com peso vivo médio inicial de 354 $\mathrm{kg}$ e idade média de 17 meses. Os animais receberam dietas contendo níveis crescentes de concentrado de: $25 ; 37,5 ; 50 ; 62,5 ;$ e $75 \%$. Houve efeito linear crescente para o consumo de $\mathrm{P}$ e decrescente para o de $\mathrm{Mg}$ e $\mathrm{K}$, com aumento dos níveis de concentrado. No entanto, para o consumo de $\mathrm{Ca}$, verificou-se comportamento quadrático, estimando-se consumo mínimo de $45,9 \mathrm{~g} / \mathrm{dia}$ para o nível de 40,99\% de concentrado na dieta.

Com relação ao consumo de sódio, foi verificado efeito linear decrescente $(\mathrm{P}<0,01)$ com a inclusão de volumoso na dieta, o que pode ser explicado pela redução da concentração de $\mathrm{Na}$ nas dietas com maiores níveis de volumoso. Em trabalhos realizados no Brasil, CARVALHO et al. (1997) verificaram comportamento quadrático para o consumo de $\mathrm{Na}$, estimando-se consumo mínimo com $20,9 \%$ de concentrado nas rações. ARAÚJO et al. (1997) verificaram comportamento quadrático para o consumo de $\mathrm{Na}$ e estimaram o consumo máximo de 29,6 g/dia com o nível de $41 \%$ de volumoso na dieta. FERREIRA (1997), entretanto, não verificou efeito de diferentes proporções volumoso:concentrado sobre o consumo de sódio.

Os coeficientes de absorção aparente de $\mathrm{Ca}, \mathrm{P}, \mathrm{Mg}$, $\mathrm{K}$ e Na, com suas respectivas equações de regressão ajustadas, e os coeficientes de variação encontram-se na Tabela 3. As absorções aparentes de $\mathrm{Ca}, \mathrm{P}, \mathrm{Mg}$ e $\mathrm{Na}$ não foram influenciados, mas a de $\mathrm{K}$ decresceu linearmente $(\mathrm{P}<0,05)$ com adição de volumoso nas dietas.

A absorção aparente de $\mathrm{Ca}$ foi, em média, de $56,06 \%$. Este valor é superior aos obtidos por COE- 
182 Rev. bras. zootec.

Tabela 2 - Médias, coeficientes de variação (CV) e equações de regressão ajustadas (ER) para os consumos diários de cálcio $(\mathrm{Ca})$, fósforo $(\mathrm{P})$, magnésio $(\mathrm{Mg})$, potássio $(\mathrm{K})$ e sódio $(\mathrm{Na})$, em gramas

Table 2 - Means, coefficients of variation (CV) and fitted regression equations (RE) for the daily intakes of calcium (Ca), phosphorus (P), magnesium $(\mathrm{Mg})$, potassium $(\mathrm{K})$ and sodium $(\mathrm{Na})$, in grams

\begin{tabular}{|c|c|c|c|c|c|c|}
\hline \multirow[t]{2}{*}{ Item } & \multicolumn{4}{|c|}{ Nível de volumoso (Forage level), \% } & \multirow{2}{*}{$\begin{array}{l}\mathrm{CV} \\
\%\end{array}$} & \multirow[t]{2}{*}{$\mathrm{ER}(R E)$} \\
\hline & 10 & 25 & 40 & 55 & & \\
\hline$\overline{\mathrm{Ca}}$ & 22,04 & 22,01 & 24,78 & 24,79 & 19,18 & $\hat{\mathrm{Y}}=23,41$ \\
\hline $\mathrm{P}$ & 8,17 & 8,86 & 12,12 & 10,08 & 19,44 & 1 \\
\hline $\mathrm{Mg}$ & 5,04 & 5,38 & 6,17 & 5,84 & 18,49 & 2 \\
\hline K & 41,66 & 47,96 & 58,74 & 61,99 & 17,86 & 3 \\
\hline $\mathrm{Na}$ & 6,38 & 5,09 & 5,77 & 4,19 & 21,59 & 4 \\
\hline \multicolumn{6}{|c|}{$\begin{array}{l}\text { 1. } \hat{\mathrm{Y}}=5,4301+0,261055^{\star *} \mathrm{NV}-0,0030786^{*} \mathrm{NV}^{2} \\
\text { 2. } \hat{\mathrm{Y}}=4,9255+0,021082^{*} \mathrm{NV} \\
\text { 3. } \hat{\mathrm{Y}}=37,0557+0,478096^{\star *} \mathrm{NV} \\
\text { 4. } \hat{\mathrm{Y}}=6,6209-0,039038^{\star *} \mathrm{NV}\end{array}$} & $\begin{aligned} \mathrm{R}^{2} & =0,65 \\
\mathrm{r}^{2} & =0,66 \\
\mathrm{r}^{2} & =0,96 \\
\mathrm{r}^{2} & =0,64\end{aligned}$ \\
\hline
\end{tabular}

Tabela 3 - Médias, coeficientes de variação (CV) e equações de regressão ajustadas (ER) para as absorções aparentes totais de cálcio $(\mathrm{Ca})$, fósforo $(\mathrm{P})$, magnésio $(\mathrm{Mg})$, potássio $(\mathrm{K})$ e sódio $(\mathrm{Na})$

Table 3 - Means, coefficients of variation (CV) and fitted regression equations (RE) for the total apparent absorption of calcium (Ca), phosphorus $(P)$, magnesium $(\mathrm{Mg})$, potassium $(K)$ and sodium $(\mathrm{Na})$

\begin{tabular}{|c|c|c|c|c|c|c|}
\hline \multirow[t]{2}{*}{ Item } & \multicolumn{4}{|c|}{ Nível de volumoso (Forage level), \% } & $\mathrm{CV}$ & \multirow[t]{2}{*}{$\mathrm{ER}(R E)$} \\
\hline & 10 & 25 & 40 & 55 & $\%$ & \\
\hline$\overline{\mathrm{Ca}}$ & 62,21 & 55,15 & 51,17 & 55,73 & 18,39 & $\hat{\mathrm{Y}}=56,06$ \\
\hline $\mathrm{P}$ & 53,82 & 47,93 & 41,03 & 48,91 & 25,95 & $\hat{\mathrm{Y}}=47,92$ \\
\hline $\mathrm{Mg}$ & 48,69 & 45,52 & 47,92 & 42,06 & 22,34 & $\hat{\mathrm{Y}}=46,05$ \\
\hline $\mathrm{K}$ & 84,48 & 83,18 & 78,35 & 79,91 & 6,57 & 1 \\
\hline $\mathrm{Na}$ & 75,44 & 66,35 & 63,23 & 64,50 & 21,73 & $\hat{\mathrm{Y}}=67,38$ \\
\hline 1. $\hat{Y}$ & & & & & & $\mathrm{r}^{2}=0,70$ \\
\hline
\end{tabular}

LHO DA SILVA et al. (1991), VALADARES FILHO et al. (1991a), RABELLO et al. (1994), ARAÚJO et al. (1994), BEN-GHEDALIA et al. (1996), CARVALHO et al. (1997) e KHORASANI et al. (1997), respectivamente, 23,40; 47,90; 32,80; 36,20; 26,$20 ; 16,32$; e 29,87\%, e próximos aos encontrados por FIELD (1983), COELHO DA SILVA, (1995) e ARAÚJO et al. (1997), respectivamente, 33 a 68\%; 15 a $68 \%$; e $52,56 \%$.

ONRC (1989 e 1996) considerou valores de 38 e $50 \%$, respectivamente, para a absorção verdadeira do $\mathrm{Ca}$.

Observou-se absorção aparente de $\mathrm{P}$, em média, de $47,92 \%$, que foi relativamente próxima às obtidas por ROSADO (1991), VALADARES FILHO et al. (1991a), ARAÚJO et al. (1994) e BEN-GHEDALIA et al. (1996), respectivamente, 45,8; 44,3; 43,6; e $42,2 \%$. Contudo, foram inferiores às encontradas por COELHO DA SILVA et al. (1991), MORA et al. (1996) e ARAÚJO et al. (1997), respectivamente, 57,$7 ; 57,48$; e $51,9 \%$.
O ARC (1980), o NRC (1989) e o AFRC (1991) consideraram valores de 50,58 e $70 \%$, respectivamente, para absorção verdadeira de $\mathrm{P}$.

Obtiveram-se absorções aparentes de $\mathrm{Mg}$, variando de 42,06 a 48,69\%, com média de $46,05 \%$, sendo próximas às encontradas por ROSADO (1991), MORA et al. (1996) e ARAÚJO et al. (1997), que foram, respectivamente, 43,7; 41,6 e 45,7\%. Contudo, foram inferiores às encontradas por RABELLO et al. (1994) e BEN-GHEDALIA et al. (1996), respectivamente, 36,6 e 37,5\%. O ARC (1980) considera valor de $20 \%$ para a absorção verdadeira de $\mathrm{Mg}$.

A absorção aparente de $\mathrm{K}$ variou de 79,91 a $84,48 \%$, com média de $81,48 \%$, sendo bastante semelhante à encontrada por ARAÚJO et al. (1997), que utilizaram dietas e animais com idade semelhantes aos deste trabalho. COELHO DA SILVA et al. (1991), ARAÚJO et al. (1994), RABELLO et al. (1994), RAHNEMA et al. (1994), BEN-GHEDALIA et al. (1996), MORA et al. (1996) e KHORASANI et 
al. (1997) também encontraram valores próximos aos deste trabalho.

De acordo com o NRC (1989), foi sugerido coeficiente de absorção verdadeira variando de 91 a 100\%.

$\mathrm{O}$ coeficiente de absorção aparente de $\mathrm{Na}$ variou de 64,50 a $75,44 \%$, com média de $67,38 \%$, sendo inferior aos encontrados por ARAÚJO et al. (1997), CARVALHO et al. (1997) e KHORASANI et al. (1997), respectivamente, 93,64; 89,10; e 76,13\%, e superiores aos encontrados por ROSADO (1991) e VALADARES FILHO et al. (1991b), respectivamente, 56,5 e 59,2\%. O ARC (1980) adotou o valor de $91 \%$ para absorção verdadeira de $\mathrm{Na}$.

\section{Conclusões}

O consumo máximo de $10,96 \mathrm{~g}$ /dia para $\mathrm{P}$ foi estimado com $42,40 \%$ de volumoso nas dietas.

Os consumos de $\mathrm{Mg}$ e K aumentaram, enquanto o de $\mathrm{Na}$ decresceu linearmente, com aumento dos níveis de feno de capim coast-cross nas dietas.

Os coeficientes de absorção aparente de $\mathrm{Ca}, \mathrm{P}$, $\mathrm{Mg}$ e $\mathrm{Na}$ não foram influenciados, enquanto de $\mathrm{K}$ decresceu linearmente com aumento dos níveis de feno de capim coast-cross nas dietas.

\section{Referências Bibliográficas}

AGRICULTURAL AND FOOD RESEARCH COUNCIL AFRC. 1991. A reappraisal of the calcium and phosphorus requirements of sheep and cattle. Report 6. Nutrition Abstract and Reviews (serie B), 61(69):573 - 612.

AGRICULTURAL RESEARCH COUNCIL - ARC. 1980. The nutrients requirements of ruminants livestock. London: Commonwealth Agricultural Bureaux. 351p.

ALFARO, E., NEATHERY, M.W., MILLER, W.J. et al. 1988. Influence of a wide range of calcium intakes on tissue distribuition of macroelements and microelements in dairy calves. J. Dairy Sci., 71(5):1295-1300.

ARAÚJO, G.G.L., COELHO DA SILVA, J.F., VALADARES FILHO, S.C. et al. 1994. Absorções aparentes totais e parciais de cálcio, magnésio, fósforo e potássio pelas vacas lactantes. R. Soc. Bras. Zootec., 23(5):773-781.

ARAÚJO, G.G.L., COELHO DA SILVA, J.F., VALADARES FILHO, S.C. et al. Consumo e absorção aparente total de macroelementos minerais ( $\mathrm{Ca}, \mathrm{P}, \mathrm{Mg}, \mathrm{Na}$ e $\mathrm{K}$ ) de dietas com diferentes níveis de volumoso. In: REUNIÃO ANUAL DA SOCIEDADE BRASILEIRA DE ZOOTECNIA, 34, Juiz de Fora, MG, 1997. Anais... Juiz de Fora: SBZ, 1997. p.237-239.

BEN-GHEDALIA, D., MIRON, J., YOSEF, E. 1996. Apparent digestibility of minerals by lactating cows from a total mixed ration supllemented with poultry litter. J. Dairy Sci., 79:454-458.

BOIN, C. 1993. Exigências de minerais pelas categorias do rebanho bovino e funções desses nutrientes. In: PEIXOTO, A.M. (Ed). Nutrição de bovinos: conceitos básicos e aplicados. Piracicaba, SP: FEALQ. p.407-450.
CARVALHO, A.U., VALADARES FILHO, S.C., COELHO DA SILVA, J.F. et al. 1997. Níveis de concentrado em dietas de zebuínos. 1. Consumo e digestibilidade aparente. R. Bras. Zootec., 26(5):986-995.

COELHODA SILVA, J.F. Exigências de macroelementos inorgânicos para bovinos: o sistema ARC/AFRC e a experiência no Brasil. In: PEREIRA, J.C. (Ed). SIMPÓSIO INTERNACIONAL SOBRE EXIGÊNCIAS NUTRICIONAIS DE RUMINANTES, 1995, Viçosa, MG. Anais... Viçosa: JARD, 1995. p.467-504.

COELHO DA SILVA, J.F., VALADARES FILHO, S.C., LEÃO, M.I. et al. 1991. Efeito da monensina sódica e da uréia sobre o consumo, parâmetros ruminais, digestibilidade aparente e balanço nutricional em bovinos. R. Soc. Bras. Zootec., 20(5):454-470.

FERREIRA, M.A. Desempenho, exigências nutricionais e eficiência de utilização da energia metabolizável para ganho de peso de bovinos $F_{1}$ Simental $x$ Nelore. Viçosa, MG:UFV, 1997. 97p. Tese (Doutorado em Zootecnia) - Universidade Federal de Viçosa, 1997.

FIELD, A.C. 1983. A review of requirements of dairy and beef cattle for major elements. Livest. Prod. Sci., 10(4):327 - 338.

GREENE, L.W., FONTENOT, J.P., WEBB JR., K.E. 1983. Site of magnesium and macromineral absorption in steers fed high levels of potassium. J. Anim. Sci., 57:503.

GREENE, L.W., MAY, B.J., SCHELLING, G.T. et al. 1988. Site and extent of apparent magnesium and calcium absorption in steers fed monensin. J. Anim. Sci., 66(11):2987-2991.

HORST, R.L. 1986. Regulation of calcium and phosphorus homeostasis in the dairy cow. J. Anim. Sci., 69:604.

JACKSON, J.A., LANGER, D.L., HEMKEN, R.W. 1988. Evaluation of content and source of phosphorus fed to dairy calves. J. Anim. Sci., 71:2187-2192.

KHORASANI, G.R., ARMSTRONG, D.G. 1990. Effect of sodium and potassium level on the absorption of magnesium and other macro-minerals in sheep. Livest. Prod. Sci., 24:223.

KHORASANI, G.R., JANZEN, R.A., McGILL, W.B. et al. 1997. Site and extent of mineral absorption in lactating cows fed whole-crop cereal grain silage or alfafa silage. J. Anim. Sci., 75(1):239-248

McDOWELL, L.R., CONRAD, J.H., ELLIS, G.L. et al. 1983. Minerals for grazing ruminants in tropical regions. Gansville: University of Flórida. 85p.

MORA, P.J.G., VALADARES FILHO, S.C., LEÃO, M.I. et al. 1996. Digestibilidade aparente dos nutrientes e energia líquida da silagem de milho (Zea mays L.) para vacas lactantes. R. Soc. Bras. Zootec., 25(2):357-368.

MORSE, D., HEAD, H.H., WILCOX, C.J. et al. 1992. Effects of concentration of dietary phosphorus on amount and route of excretion. J. Dairy Sci., 75:3039.

NATIONAL RESEARCH COUNCIL - NRC. 1989. Nutrient requirements of dairy cattle. 6.ed. Washington, D.C. 157 p.

NATIONAL RESEARCH COUNCIL - NRC. 1996. Nutrient requirements of beef cattle. 7.ed. Washington, D.C: National Academy Press. $242 \mathrm{p}$.

RABELLO, T.G., VALADARES FILHO, S.C., COELHO DA SILVA, J.F. et al. Absorções aparentes totais e parciais de cálcio, fósforo, sódio, potássio e magnésio em vacas alimentadas com grão de soja moído. In: REUNIÃO ANUAL DA SOCIEDADE BRASILEIRA DE ZOOTECNIA, 31, Maringá, PR, 1994. Anais... Maringá: SBZ, 1994. p.418.

RAHNEMA, S.H., WU, Z., OHAJURUKA, O. A. et al. 1994. Site of mineral absorption in lactating cows fed high-fat diets. J. Anim. Sci., 72:229.

REID, R.L., TEMPLETON JR., W.C., RANNEY, T.S. et al. 1987. 
184 Rev. bras. zootec.

Digestibility, intake and mineral utilization of combinations of grasses and legumes by lambs. J. Anim. Sci., 64:1725.

ROSADO, M. Efeito do complexo ácido graxo-cálcio sobre a digestibilidade aparente, alguns parâmetros ruminais e taxa de passagem em vacas lactantes. Viçosa, MG:UFV, 1991. 96p. Dissertação (Mestrado em Zootecnia) - Universidade Federal de Viçosa, 1991.

SIGNORETTI, R.D., COELHO DA SILVA, J.F., VALADARES FILHO, S.C. et al. 1999. Consumo e digestibilidade aparente em bezerros da raça Holandesa alimentados com dietas contendo diferentes níveis de volumoso. Rev. bras. zootec., 28(1):169-177.

SILVA, D.J., 1990. Análise de alimentos (Métodos químicos e biológicos). Viçosa, MG:UFV. 196p.

TEIXEIRA, J.C. 1992. Nutrição de ruminantes. Lavras, MG: FAEPE p.123-136.

VALADARES FILHO, S.C., COELHO DA SILVA, J.F., LEÃO, M.I. et al. Absorções aparentes totais e parciais de cálcio e fósforo em bovinos alimentados com ração purificada e semipurificada. In: REUNIÃO ANUAL DA SOCIEDADE BRASILEIRA DE ZOOTECNIA, 28, João Pessoa, PB, 1991. Anais... João Pessoa: SBZ, 1991a. p.178.
VALADARES FILHO, S.C., COELHO DA SILVA, J.F., LEÃO, M.I. et al. Absorções aparentes totais e parciais de sódio, potássio, magnésio, cobre e manganês em bovinos alimentados com ração purificada e semipurificada. In: REUNIÃO ANUAL DA SOCIEDADE BRASILEIRA DE ZOOTECNIA, 28, João Pessoa, PB, 1991. Anais... João Pessoa: SBZ, 1991b. p.179.

Recebido em: 08/04/98

Aceito em: 20/08/98 